\title{
Preface
}

\section{Special Section to Commemorate the 30th Anniversary of Advances in Atmospheric Sciences}

DOI: $10.1007 / \mathrm{s} 00376-014-0012-y$

The first issue of Advances in Atmospheric Sciences (AAS) was published in 1984. Originally quarterly, the journal later became bimonthly and will now be published monthly starting from 2015. AAS is sponsored by the Chinese Committee of Meteorology and Atmospheric Physics (CCMAP) — which later evolved into Chinese National Committee for International Association of Meteorology and Atmospheric Sciences (IAMAS) — and the Institute of Atmospheric Physics (IAP) and it is now jointly published by Springer and Science Press. The main purpose of the journal is to publish original research papers by Chinese and international contributors and to exchange scientific ideas and discoveries among the members of this worldwide research community.

As the opening preface back in 1984 announced, most of the scientific papers published in AAS describe the latest achievements and developments in the atmospheric sciences and marine meteorology, including the associated fields of dynamical and physical oceanography, as well as the theoretical and practical aspects of these important subjects. Papers describing new applications of meteorological methods or data, or new techniques—instrumental or mathematical—intended for use in atmospheric research, may also be accepted.

Three decades have passed since the first issue of AAS was published. In that time, accompanied by rapid scientific and technological development, as well as major advancements in the economic and societal application of these developments throughout the world, AAS has continued to adapt its scientific depth and scope, covering topics such as the climate system and climate change (including its natural and anthropological influences on extreme weather and climate events), regional and global environments, atmospheric physics and chemistry, satellite and ground-based remote sensing, and advanced atmospheric exploration. AAS has also expanded its disciplinary content to earth system science, biogeophysics and biogeochemistry, and land surface processes. As the editors at the time of the first issue expected, AAS has become an international journal with an increasing citation rate and visibility from the worldwide scientific community.

To celebrate the 30th anniversary of AAS, a special collection of invited papers has been organized that reflects the current and emerging hot topics in our field. The authors of these papers are well-known scientists in their respective areas. The publication of these papers is divided across the first two issues of the current volume: AAS 32(1) and AAS 32(2). The journal editors express their appreciation not only to the distinguished contributors of the invited papers, but also to all AAS authors, editors and readers who have helped build the journal's reputation and standing over the past 30 years.

LÜ Daren, ZHU Jiang, Ming XUE

Editors-in-Chief

Advances in Atmospheric Sciences 